\title{
The processing of spatial frequency and orientation information
}

\author{
FOOK KEE CHUA \\ University of California, Los Angeles, California
}

\begin{abstract}
Three identification experiments were completed to disambiguate the associations between spatial frequency and orientation information at the sensory, decisional, and response levels. The stimuli were gratings generated by crossing four levels each of spatial frequency and orientation. In Experiment 1, the subjects made a single identification response to the stimuli. In Experiment 2 , two identification responses were made, one for the spatial frequency component and the other for the orientation component. In Experiment 3, the subjects identified either the spatial frequency or the orientation component in any block of trials. The data were confusion ma. trices, and an information-transmission approach was used to investigate the interactions in the system. The results show that although there were sensory associations, there were no interactions at the decisional level. Performance parity was found: there was no significant difference between the single- and double-judgment paradigms in terms of information transmitted. Overall, the results suggest that although spatial frequency and orientation information is coded jointly at the sensory level, subsequent processing is independent, with each dimension drawing upon different attentional resources.
\end{abstract}

Over the last couple of decades, the conceptual tool that has been most widely used to describe the processing of visual stimuli is spatial frequency analysis. The general model that underlies this approach is one that characterizes the visual system as having (hypothetical) multiple pathways that are spatially tuned. The tuning characteristics of any such pathway may be described in terms of its contrast, orientation, spatial frequency, position, and phase.

There are good psychophysical data supporting the idea of mechanisms selectively sensitive to spatial frequency and orientation (Graham, 1981; Olzak \& Thomas, 1986). The physiological substrate of these mechanisms is not generally defined, but could be single neurons at the visual cortex (Graham, 1985). Evidence from single-cell recordings show that these cells are selective in their responses to different orientations (Hubel \& Wiesel, 1962, 1968) and spatial frequencies (Schiller, Finlay, \& Volman, 1976). There is thus some sort of parallel between the notion of pathways subserving different spatial characteristics and the neural organization of the cortex.

A question that follows from this general model is whether the tuning of the different spatial characteristics is separable. Nonseparability of spatial frequency and

This paper is based on portions of a doctoral dissertation submitted to UCLA. The research was supported in part by U.S. Public Health Service Grant EY00360 from the National Eye Institute to James P. Thomas. The author's thanks are extended to James Thomas and Thomas Wickens for valuable suggestions, criticisms, and discussions, to Sarah Spence, who helped in data collection, and to Lester Krueger and two anonymous reviewers for their insightful comments on earlier drafts. The author's mailing address is Department of Social Work and Psychology, National University of Singapore, Kent Ridge Crescent, Singapore 0511 . orientation could mean, for example, that selectivity with respect to frequency would not be the same at all orientations.

Experiments that have investigated spatial frequency and orientation in tandem, or in the same domain, have been few and far between (Caelli, 1983). In fact, many psychophysical experiments have, implicitly at least, assumed that the tuning for frequency and orientation is separable (Daugman, 1984). Similarly, physiological studies aimed at mapping the receptive-field profiles of cortical cells have generally assumed polar separability between frequency and orientation (Daugman, 1980; Webster \& DeValois, 1985). This assumption is basically incorrect, because although the predicted receptive field is circular and symmetric in the two-dimensional Fourier plane, there is physiological evidence contradicting such a model (Daugman, 1984, 1985; but see Glezer, Tsherbach, Gauselman, \& Bondarko, 1982, for an alternative view).

By and large, the psychophysical experiments that have investigated the issue of processing independence have employed a filtering paradigm. The subject is required to discriminate one of the variables (say, spatial frequency) while the other variable (say, orientation) is varied systematically. The extent to which variation in the second variable affects performance is interpreted as evidence that the two variables are not processed separately.

Burbeck and Regan (1983) used stimuli that were formed by crossing two orientations (vertical and horizontal) with two spatial frequencies ( 2 and 5 cycles per degree). The results were that frequency and orientation discriminations were largely independent of each other. Bradley and Skottun (1984), using a matching method, and Caelli, Brettel, Rentschler, and Hilz (1983), employ- 
ing the method of adjustment, came to essentially the same conclusions. Blakemore and Nachmias (1971) used a selective adaptation method and found that adaptation to a grating of a particular spatial frequency was greatest when the test grating was of the same orientation. When the orientation of the adaptation grating was markedly different from the test grating, no transfer was found. In an experiment in which both frequency and orientation were jointly varied, Caelli and Moraglia (1985) reported results that suggested that frequency and orientation were coded jointly.

\section{Sources of Interaction}

The filtering paradigm has been used to investigate the extent to which the system is able to attend to one dimension and filter out the rest. Thus, the issue that it examines is whether the dimensions are separable. Dimensional separability, however, does not guarantee that there would be no interactions in the system when all the dimensions are processed concurrently. For example, even if the dimensions are separable, interactions could arise if the decision on one dimension is affected by decisions on the other dimensions.

Consider an experiment in which a stimulus constituted of $F$ and $O$ components is presented. The subject makes two identification responses, $f$ and $o$, to the respective stimulus components. Although the information-processing sequence is a continuous one, it is nonetheless useful to distinguish between the sensory and the cognitive (decisional) levels. The functional properties of the representation at the different levels are probably different, and this is likely to impose different sorts of processing constraints.

This sensory/cognitive distinction makes distinguishable three different types of interactions within the perceptual system. At the sensory level, one may examine whether the (neural) representation of the $F$ and $O$ components are encoded independently of each other. This is related to the issue of the tuning characteristics of the different dimensions. Call this the sensory independence issue.

Next, consider how this sensory information is interpreted; here the issue is whether there is independence at the cognitive level (the cognitive independence issue). This distinction between independence at the sensory and cognitive levels parallels Garner and Morton's (1969) distinction between state and process models. There are two separate issues to consider here: (1) dimensional separability and (2) decisional independence. The latter obtains when the decision on the $o$ response is made solely on the basis of $O$, and the $f$ response on $F$.

The third source of interactions in the system could occur at the response level. In a sense, assessing response independence may be thought of as ruling out a nuisance factor so that the magnitude of associations at the sensory and cognitive levels is uncontaminated by associations at the response end. There are two sorts of response correlations that might be considered. First, there could be a general response bias, in which a particular combination of responses are preferred over others. Second, for each stimulus, there could be a distinct response pattern. These response associations will be referred to as error correlations, following Garner and Morton's (1969) nomenclature.

\section{Measuring Information Transmission in the System}

Various approaches have been adopted to investigate these independence issues within an identification paradigm. For example, Getty, Swets, Swets, and Green (1979) used a multidimensional scaling (MDS) approach, whereas Nosofsky (1985) adapted the Luce choice model to various models of independence.

The approach here partitions the information transmitted within the system into the orthogonal parts that are relevant to the issues of cognitive, sensory, and response independence (see the Appendix for a brief explication). Assessment of cognitive independence is relatively straightforward: to the extent that cognitive independence holds, cross-component transmission should not exist; for example, information from one component (say, $F$ ) should not affect the decision on other components (say, the $o$ response). The partial contingency measures$U_{F}(O: f)$ and $U_{o}(F: o)$-that reflect such cross-component transmission should have zero magnitudes. Ashby and Townsend (1986) have shown formally that dimensional separability and decisional independence imply that the partial contingency terms (or, to use their equivalent concept, marginal response invariance) have zero values. Note, however, Ashby and Townsend's caveat that testing the magnitude of the partial contingent-uncertainty terms to assess if dimensional separability and decisional independence hold is tantamount to working the implication backwards.

To assess if sensory independence holds, measures that pertain to the state of the organism are needed. Sensory independence may be conceptualized as a condition in which the state of the mechanisms that encode $F$ is independent of those that encode $O$. One way of assessing state independence is to check whether performance on one component is correlated with performance on the other; if the components are encoded independently, there should be no correlation between performance on the two components. Garner and Morton (1969) referred to the condition of zero correlation as state independence, whereas Ashby and Townsend (1986) called it sampling independence. (The latter argued that for sensory independence to hold, the additional condition of decisional independence must obtain; see their Theorem 1.) Denote correct responses on the frequency and orientation components as $f_{c}$ and $o_{c}$, respectively. If there is an association between correct responses on both components, the magnitude of the partial contingency measure, $U_{F o}\left(f_{c}: o_{c}\right)$, will be large, thus implying state dependence.

The two measures that reflect response correlations are the simple contingency measure, $U(f: o)$, which reflects 
the magnitude of general response bias, and the partial term, $U_{F o}(f: o)$, which may be taken as a measure of error correlation.

\section{The Experiments}

The double-judgment paradigm was employed to investigate whether a particular stimulus component would give rise to different patterns of identification errors when it is combined with different levels of another stimulus component. For example, if there are no interactions in the system, then it might be expected that the same kinds of confusion errors would be made on the spatial frequency component irrespective of whichever orientation component was combined with it. Although the evidence from experiments using the filtering paradigm has shown that, in spatial frequency discrimination, the orientation dimension could be filtered out (e.g., Burbeck \& Regan, 1983), the paradigm here is different in that both components are attended to. The issue here is whether, in making two decisions simultaneously, the decision made on one affects the other (and vice versa).

Three experiments were completed. In the first experiment, the subjects were required to make a single identification response to the stimuli. In Experiment 2, the subjects made two responses. The rationale for these two experiments was to determine whether paradigmatic differences would affect the results.

Related to the idea of cognitive independence is the notion of performance parity. Performance parity obtains when performance in identifying any component in a simultaneous task equals performance when only that single component is attended to (i.e., a single-judgment task). Cognitive independence is a precondition for, but does not guarantee, performance parity. Parity in performance could mean that different resources are deployed in identifying the two components. To test if parity obtains, that is, whether performing two identification tasks simultaneously leads to performance decrement, a control experiment (Experiment 3) was run, in which the subjects attended to and identified only a single component. Experiment 1 was run first; Experiments 2 and 3 were run together.

\section{GENERAL METHOD}

\section{Subjects}

Two subjects participated in all three experiments. Subject 1 is the author, and Subject 2, a female graduate student, was naive about the hypothesis. Both are corrected myopes. They were highly trained in discriminating between pairs of gratings before embarking on the experiments.

\section{Stimuli and Apparatus}

The stimulus set for all three experiments consisted of 16 stimuli obtained by crossing four spatial frequency and four orientation values. The values for each subject were adjusted according to the subject's performance in a "yes-no" discrimination task. The frequency and orientation levels were varied over only a small range to ensure that the discrimination performance between adjacent levels was about $60 \%$ (measured by area under the ROC curve). If the range had been made wider, the task would be too simple, leading
Table 1

Stimulus Values for Experiments

\begin{tabular}{cc}
\hline Spatial Frequency & Orientation \\
\hline 3.90 & 0.2 \\
3.95 & 0.5 \\
4.00 & 0.8 \\
4.05 & 1.1 \\
\hline
\end{tabular}

Note-spatial frequency is defined in cycles per degree. Orientation (in degrees) is defined as clockwise deviation from zero (vertical).

to a semidegenerate confusion matrix with entries clustering only along the major diagonal. The spatial frequency values were centered on 4.0 cycles per degree (cpd); the orientation values were clockwise deviations from the vertical $\left(0^{\circ}\right)$. The values for both subjects are presented in Table 1 .

The same viewing conditions held for all three experiments. The stimuli were generated digitally on a Cromemco CS-2 minicomputer and were passed through a 12-bit digital-to-analog converter. The patterns were displayed on a Tektronix 608 monitor with a P31 phosphor, which is a fast-decaying (to $1 \%$ of its intensity within $0.25 \mathrm{msec}$ after display offset) phosphor with a greenish tint. The mean luminance of the display was $150 \mathrm{~cd} / \mathrm{m}^{2}$. The display raster was generated by applying the appropriate ramp and triangular voltages to the $X$ and $Y$ axes; the stimulus gratings were formed by driving the $Z$ axis with computer-generated waveforms. The screen was masked by a surround, matched in luminance and chromaticity to the display, to provide a $3^{\circ}$ circular viewing field.

Each stimulus appeared for $1 \mathrm{sec}$. The stimulus was signaled by the onset of a tone. The stimuli-Gabor packets-were essentially sine-wave gratings windowed by a Gaussian function. The Gaussian envelope had a standard deviation of $167 \mathrm{msec}$ and a space constant of 4.0 cycles. All stimuli were viewed binocularly. A headrest against the back of the head ensured that a constant viewing distance of $1.5 \mathrm{~m}$ was maintained.

\section{EXPERIMENT 1}

\section{Procedure}

The subjects made absolute identification judgments on the set of 16 stimuli. Before the actual trials, the subjects learned the numerical labels that were randomly assigned to each stimulus. The identification task required the subjects to discriminate between the stimuli and respond with the stimulus's numerical label. It was important that the memory component of the task be eliminated or, at the very least, minimized, so that the data reflect only identification errors.

A pilot test of the experiment showed that even with a set of perfectly discriminable stimuli, a substantial number of errors were made. The subjects reported that they had great difficulty remembering the numerical labels. To get around the memory requirements of the task, the 16 stimuli were presented in subsets of four stimuli created by crossing two spatial frequency and two orientation levels. For the entire stimulus set, there were therefore 36 subsets of these $2 \times 2$ combinations. Each of the 16 stimuli appeared in nine subsets.

The order of presentation of the 36 subsets was random. The subjects were not told of the identity of the stimuli (e.g., they did not know that 3.9 vs. 4.0 cpd stimuli were used for a particular block of trials), although previews were provided to acquaint them with the stimuli. Each block consisted of 64 trials (each of the four stimuli presented 16 times). Six or seven blocks were completed in each 1-h session per day. In all, each stimulus was judged 144 times.

\section{Results}

The data were 36 subsets of 2 (frequency:stimulus) $\times$ 2 (frequency:response) $\times 2$ (orientation:stimulus) $\times 2$ 
(orientation:response) confusion matrices. Owing to the experimental constraints, each matrix subtable was analyzed separately.

For each subtable, the two partial contingency measures, $U_{F}(O: f)$ and $U_{O}(F: o)$, were determined; for the omnibus test, these measures were summed across all 36 subtables and tested against the null hypothesis of zero information.

The magnitude of these measures should be zero for cognitive independence to hold. It has been shown (Miller \& Madow, 1954, and McGill, 1954, who extended it to the multivariate case) that if $I$ is the maximum likelihood estimate of transmitted information, then the quantity $G^{2}$ $=1.3863 N I$ (where $N$ is the total frequency) has a chisquare distribution under the null hypothesis. Thus, given the appropriate degrees of freedom, it is possible to test whether the magnitude of information transmission represents substantive quantities or merely sampling fluctuations.

No interaction was detected at the cognitive level. For both subjects, neither partial contingent-uncertainty term was statistically significant. The test statistics for Subject 1's data are: $U_{F}(O: f)=.86, G^{2}(72)=76.59, p=$ .33 , and $U_{o}(F: o)=.57, G^{2}(72)=50.79, p=.97$. The corresponding statistics for Subject 2 are: $U_{F}(O: f)=.89$, $G^{2}(72)=79.20, p=.26$, and $U_{o}(F: o)=.78, G^{2}(72)$ $=68.93, p=.58$.

To obtain the measure $U_{F o}\left(f_{c}: o_{c}\right)$, each subtable was reclassified so that for each $F_{i} O_{j}$, the rows and columns were correct/incorrect frequency responses and correct/incorrect orientation responses, respectively. However, since each subtable was of dimension $2 \times 2 \times 2$ $\times 2$, the measure $U_{F O}\left(f_{c}: o_{c}\right)$ is the same as the error correlation term $U_{F o}(f: o)$. For both subjects, this measure was significant. The test statistics are: for Subject 1 , $U_{F o}(f: o)=5.48, G^{2}(144)=486.72, p<.0001$, and for Subject 2, $U_{F o}(f: o)=5.44, G^{2}(144)=483.14$, $p<.0001$.

\section{Discussion}

The results are consistent for both subjects: independence at the cognitive level is suggested. It is possible that the experimental manipulation failed to bias the subjects to adopt what may be called a holistic processing strategy. The subjects could still have processed the components separately and then put the two decisions together into a composite response. Be that as it may, it is worth noting that despite efforts to bias the subjects, cognitive independence was still found.

However, state independence is not supported: the $U_{F o}\left(f_{c}: o_{c}\right)$ term for both subjects was significantly different from zero. Taken together, this would mean that sensory independence is not supported by the data.

\section{EXPERIMENT 2}

\section{Procedure}

In Experiment 2, two judgments were made. The same set of 16 stimuli was used. Each block consisted of 96 trials (each of the 16 stimuli presented six times). A total of 48 blocks were run, 24 blocks in each of two replications. The subjects made the frequency judgment before the orientation judgment for half the blocks; on the other half, the orientation judgment was made first. Each stimulus was judged 144 times per replication. Otherwise, the method was the same as in Experiment 1.

Table 2

Information-Transmission Statistics for Experiment 2

\begin{tabular}{|c|c|c|c|c|c|c|}
\hline \multirow[b]{2}{*}{ Source } & \multicolumn{2}{|c|}{ 1st Replication } & \multicolumn{2}{|c|}{ 2nd Replication } & \multicolumn{2}{|c|}{ Total } \\
\hline & Frequency & Orientation & Frequency & Orientation & Frequency & Orientation \\
\hline \multicolumn{7}{|c|}{ Subject 1} \\
\hline $\begin{array}{l}U(O: o) \\
U(F: f)\end{array}$ & $\begin{array}{l}.096^{*} \\
.210^{*}\end{array}$ & $\begin{array}{l}.125^{*} \\
.270^{*}\end{array}$ & $\begin{array}{l}.127^{*} \\
.413^{*}\end{array}$ & $\begin{array}{l}.190^{*} \\
.449^{*}\end{array}$ & $\begin{array}{l}.110^{*} \\
.295^{*}\end{array}$ & $\begin{array}{l}.154^{*} \\
.347^{*}\end{array}$ \\
\hline $\begin{array}{l}U_{F}(O: f) \\
U_{o}(F: o)\end{array}$ & $\begin{array}{l}.029 \\
.019\end{array}$ & $\begin{array}{l}.027 \\
.029\end{array}$ & $\begin{array}{l}.023 \\
.023\end{array}$ & $\begin{array}{l}.031 \\
.021\end{array}$ & $\begin{array}{l}.015 \\
.009\end{array}$ & $\begin{array}{l}.013 \\
.014\end{array}$ \\
\hline $\begin{array}{l}U_{F o}(o: f) \\
U(o: f)\end{array}$ & $\begin{array}{l}.146^{*} \\
.046^{*}\end{array}$ & $\begin{array}{l}.139^{*} \\
.031^{*}\end{array}$ & $\begin{array}{l}.090 \\
.007\end{array}$ & $\begin{array}{l}.082 \\
.005\end{array}$ & $\begin{array}{l}.067^{*} \\
.019^{*}\end{array}$ & $\begin{array}{l}.061 \\
.011^{*}\end{array}$ \\
\hline$U_{F o}\left(o_{c}: f_{c}\right)$ & $.329 *$ & $.284^{*}$ & $.168^{*}$ & $.153^{*}$ & $.163 *$ & $.179^{*}$ \\
\hline \multicolumn{7}{|c|}{ Subject 2} \\
\hline $\begin{array}{l}U(O: o) \\
U(F: f)\end{array}$ & $\begin{array}{l}.060^{*} \\
.091^{*}\end{array}$ & $\begin{array}{l}.070^{*} \\
.081^{*}\end{array}$ & $\begin{array}{l}.053^{*} \\
.131^{*}\end{array}$ & $\begin{array}{l}.080^{*} \\
.066^{*}\end{array}$ & $\begin{array}{l}.054^{*} \\
.107^{*}\end{array}$ & $\begin{array}{l}.071^{*} \\
.070^{*}\end{array}$ \\
\hline $\begin{array}{l}U_{F}(O: f) \\
U_{o}(F: o)\end{array}$ & $\begin{array}{l}.018 \\
.019\end{array}$ & $\begin{array}{l}.039 \dagger \\
.023\end{array}$ & $\begin{array}{l}.023 \\
.012\end{array}$ & $\begin{array}{l}.026 \\
.030\end{array}$ & $\begin{array}{l}.010 \\
.008\end{array}$ & $\begin{array}{l}.017 \ddagger \\
.012\end{array}$ \\
\hline $\begin{array}{l}U_{F O}(o: f) \\
U(o: f)\end{array}$ & $\begin{array}{l}.115 \ddagger \\
.024^{*}\end{array}$ & $\begin{array}{l}.168 * \\
.042^{*}\end{array}$ & $\begin{array}{l}.133^{*} \\
.021^{*}\end{array}$ & $\begin{array}{l}.156^{*} \\
.043^{*}\end{array}$ & $\begin{array}{l}.066^{*} \\
.017^{*}\end{array}$ & $\begin{array}{l}.093^{*} \\
.034 *\end{array}$ \\
\hline$U_{F o}\left(o_{c}: f_{c}\right)$ & $.194^{*}$ & $.267^{*}$ & $.149 *$ & $.286^{*}$ & $.090^{*}$ & $.195^{*}$ \\
\hline
\end{tabular}

Note-1st Replication $=$ first block of 2,304 trials. 2 nd Replication $=$ second block of 2,304 trials. Total $=$ combined first and second blocks. Frequency $=1,152$ trials in which the spatial frequency response was given first. Orientation $=1,152$ trials in which the orientation response was given first. $U(O: O)$ and $U(F: f)$ $=$ simple contingent-uncertainty statistics. $U_{F}(O: f)$ and $U_{o}(F: o)=$ statistics relevant to the cognitive independence issue. $U_{F o}(o: f)$ and $U(o: f)=$ statistics relevant to the response independence issue. $U_{F o}\left(o_{c}: f_{c}\right)$ $=$ statistic relevant to the sensory independence issue. ${ }^{*} p<.0001 . \quad \dagger_{p}<.005 . \quad \ddagger p<.05$. 
Table 3

Partial Contingent-Uncertainty Statistics for Subject 2 (Data from Experiment 2, First Replication)

\begin{tabular}{|c|c|c|c|c|c|c|c|}
\hline \multicolumn{4}{|c|}{$\begin{array}{c}\text { Orientation Response } \\
\text { Made First }\end{array}$} & \multicolumn{4}{|c|}{$\begin{array}{c}\text { Collapsed Across } \\
\text { Type of First Response }\end{array}$} \\
\hline \multirow{2}{*}{$U_{F 1}(O: f)$} & \multicolumn{2}{|c|}{$=.02447$} & $=.3695$ & $U_{F 1}(O: f)$ & \multicolumn{2}{|c|}{$=.01002$} & $=.5339$ \\
\hline & 26 & 15 & 6 & 10 & 57 & 31 & 7 \\
\hline 2 & 27 & 1 & 3 & & & & \\
\hline 2 & 37 & 1 & 3 & 46 & 66 & & \\
\hline 22 & 31 & 18 & 1 & 41 & 67 & 32 & 4 \\
\hline \multicolumn{4}{|c|}{$U_{F 2}(O: f)=.0639, p=.0024$} & \multicolumn{4}{|c|}{$U_{r 2}(O: f)=.02154, p=.0456$} \\
\hline 21 & 21 & 24 & 6 & 38 & 47 & 47 & 12 \\
\hline & & & 3 & & & & \\
\hline IC & 37 & & 2 & & & & \\
\hline 18 & 37 & & 6 & 30 & 70 & & 11 \\
\hline \multicolumn{4}{|c|}{$U_{r 3}(O: f)=.04758, p=.0252$} & \multicolumn{4}{|c|}{$U_{r j}(O: f)=.01670, p=.1481$} \\
\hline 16 & 22 & 26 & 8 & 23 & 47 & 56 & 18 \\
\hline 1 & 15 & & 5 & 27 & & & 15 \\
\hline 19 & 1 & & 6 & & & & \\
\hline 4 & 29 & 29 & 10 & 16 & 46 & 52 & 30 \\
\hline \multicolumn{4}{|c|}{$U_{F 4}(O f f)=.02004, p=.5342$} & \multicolumn{4}{|c|}{$U_{F 4}(O: f)=.00534, p=.8931$} \\
\hline 8 & 21 & 24 & 19 & 18 & 41 & 47 & 38 \\
\hline 11 & 23 & 15 & 25 & 21 & 43 & 4 & 39 \\
\hline 13 & 1 & & 20 & 17 & 36 & 4 & 45 \\
\hline 9 & 22 & 25 & 16 & 16 & 43 & 51 & 34 \\
\hline \multicolumn{4}{|c|}{$U_{F}(O: f)=.03900, p=.0042$} & \multicolumn{4}{|c|}{$U_{r}(O: f)=.01340, p=.2023$} \\
\hline
\end{tabular}

Note-The rows and columns of the matrices are $O$, and $f_{j}$, respectively. Correct responses are in italic. $U_{F i}=$ partial contingent-uncertainty statistic at each $F_{t}, U_{F}(O: f)=$ omnibus measure. The $p$ value is the probability that $U_{F i}(O: f)=0$.

\section{Results}

The data were $16 \times 16$ confusion matrices. The information-transmission statistics are presented in Table 2.

The partial cross-contingency terms, $U_{F}(O: f)$ and $U_{o}(F: o)$, were tested against the null hypothesis of zero information. For Subject 1, neither term was significantly different from zero for either replication. For Subject 2, the $U_{F}(O: f)$ term was significant for the first replication data in which the orientation response was given first. This violation was also reflected in the analysis of the combined data. The association found in Subject 2's data was asymmetric: only the frequency response was affected by the orientation component. To examine where the violation lies, the data were reconstituted into four $4 \times 4$ matrices (see left column of Table 3 ), with each matrix corresponding to a different $F i$. The rows and columns of the matrices correspond to $O_{i}$ and $f_{j}$, respectively.

The violations occurred only at $F_{2}$ and $F_{3}$. However, when Subject 2's data were collapsed across type of first response (see right column of Table 3 ), the violation disappeared $\left[U_{F}(O: f)=0.0134, p=.202\right.$, and $U_{o}(F: o)$ $=0.0188, p=.394]$.

For the first-replication data, both subjects showed error correlations and response biases [the $U_{F o}(o: f)$ and $U(o: f)$ terms, respectively]. For Subject 1 , these biases disappeared in the second replication, but for Subject 2, error correlations and response biases were found in both replications. The violations persisted even when the data were collapsed across type of first response.
To test for state independence, the association measure, $U_{F o}\left(f_{c}: o_{c}\right)$, was computed. The statistic is reported in Table 2 . The results are consistent across both subjects. State independence was not found for any of the trial blocks. The data were then collapsed across the type of first response and then across replication and reanalyzed. The magnitude of the association measure, $U_{F o}\left(f_{c}: o_{c}\right)$, was significantly large in all the data.

\section{Discussion}

The results from Experiment 2 provide additional support for independence at the cognitive level. Except for one block of Subject 2's first-replication data, the partial contingent-uncertainty terms were not significantly different from zero. This violation disappeared in the second replication and when the data in the first replication were collapsed across type of first response. The violation of the independence condition could well be due to initial performance instability. Overall, the results suggest independence at the cognitive level: information on the frequency component did not affect the orientation decision, mutatis mutandis for information on the orientation component.

The data support decisional independence. However, for sensory independence to hold, state independence must also be demonstrated. This was not found. For both subjects, the measure $U_{F o}\left(f_{c}: o_{c}\right)$ was significant, implying that there was a positive association between correct identification of one component with correct identification of the other. This association cannot be simply explained away as something that was caused by response bias or error correlations, as Subject 1's second-replication data show.

\section{EXPERIMENT 3}

\section{Procedure}

The set-up for Experiment 3 was identical to that of Experiment 2. The same set of 16 stimuli was used. A total of 24 blocks of trials, each consisting of 96 trials, were run. Only one response was made per trial. At the start of any block, the subjects were told to attend to either the frequency or the orientation component. For 12 blocks, the subjects made frequency judgments; for the remaining 12 blocks, orientation judgments were made.

Experiment 3 was run concurrently with Experiment 2. In each 1-h session, the subject ran six blocks of 96 trials, three each for the double- and single-judgment experiments.

\section{Results and Discussion}

The measures that pertain to the parity issue are the $U(F: f)$ and $U(O: o)$ statistics. These measures were computed from data obtained from the single- and doublejudgment experiments and were compared. For the singlejudgment experiment, the data were $4 \times 4$ matrices. For the double-judgment experiment, collapsing across one stimulus-response pair also yielded matrices of similar dimensions. The data were analyzed two ways. First, $U(F: f)$ for the double-judgment experiment was determined from the data gathered from trials in which the frequency response was given first. Similarly, the $U(O: O)$ 
Table 4

Comparison of Information-Transmission Statistics of the Double(Experiment 2) and Single-Judgment (Experiment 3) Experiments.

\begin{tabular}{|c|c|c|c|c|c|c|}
\hline \multirow[b]{2}{*}{ Source } & \multicolumn{3}{|c|}{ Subject 1} & \multicolumn{3}{|c|}{ Subject 2} \\
\hline & Single & Double* & Double $†$ & Single & Double* & Double $†$ \\
\hline \multicolumn{7}{|c|}{ 1st Replication } \\
\hline $\begin{array}{l}U(F: f) \\
p\end{array}$ & .3169 & $\begin{array}{l}.2102 \\
.2875\end{array}$ & $\begin{array}{l}.2356 \\
.3425\end{array}$ & .1393 & $\begin{array}{l}.0915 \\
.2829\end{array}$ & $\begin{array}{l}.0825 \\
.2375\end{array}$ \\
\hline $\begin{array}{l}U(O: o) \\
p\end{array}$ & .1545 & $\begin{array}{l}.1255 \\
.3879\end{array}$ & $\begin{array}{l}.1075 \\
.3100\end{array}$ & .1556 & $\begin{array}{l}.0700 \\
.1394\end{array}$ & $\begin{array}{l}.0597 \\
.0986\end{array}$ \\
\hline \multicolumn{7}{|c|}{ 2nd Replication } \\
\hline $\begin{array}{l}U(F: f) \\
p\end{array}$ & .3474 & $\begin{array}{l}.4133 \\
.4060\end{array}$ & $\begin{array}{l}.4171 \\
.3885\end{array}$ & .1490 & $\begin{array}{l}.1307 \\
.4288\end{array}$ & $\begin{array}{l}.0930 \\
.2601\end{array}$ \\
\hline $\begin{array}{l}U(O: o) \\
p\end{array}$ & .1591 & $\begin{array}{l}.1902 \\
.4034\end{array}$ & $\begin{array}{l}.1503 \\
.4779\end{array}$ & .1488 & $\begin{array}{l}.0805 \\
.2017\end{array}$ & $\begin{array}{l}.0651 \\
.1312\end{array}$ \\
\hline \multicolumn{7}{|c|}{ Combined } \\
\hline $\begin{array}{l}U(F: f) \\
p\end{array}$ & .3288 & $\begin{array}{l}.2950 \\
.4409\end{array}$ & $\begin{array}{l}.3145 \\
.4892\end{array}$ & .1402 & $\begin{array}{l}.1073 \\
.3571\end{array}$ & $\begin{array}{l}.0853 \\
.2490\end{array}$ \\
\hline $\begin{array}{l}U(O: o) \\
p\end{array}$ & .1545 & $\begin{array}{l}.1255 \\
.3879 \\
\end{array}$ & $\begin{array}{l}.1280 \\
.4037\end{array}$ & .1556 & $\begin{array}{l}.0700 \\
.1398\end{array}$ & $\begin{array}{l}.0604 \\
.1011 \\
\end{array}$ \\
\hline
\end{tabular}

Note- $p$ values represent the probability that the single- and double-judgment data are from the same population. *For the $U(F: f)$ measure, data are from blocks in which the spatial frequency judgments were made first; for the $U(O: o)$ measure, data are from blocks in which the orientation judgments were made first. †Data averaged across type of first judgment.

statistic was computed from the trial blocks in which the orientation judgment was the first response. Then the data were collapsed across type of first judgment, and the $U(F: f)$ and $U(O: 0)$ statistics were determined.

To test if the information-transmission measures from the single- and double-judgment paradigms are statistically equivalent, a ratio test (of two chi-squares) was made (Pearson, Stouffer, \& David, 1932). The informationtransmission statistics and the $p$ values of the ratio test are reported in Table 4 . There is no significant difference between the information-transmission measures from the single- and double-judgment paradigms. The data, especially those of Subject 1, support a parity model. One interpretation of these results could be that the processing of spatial frequency and orientation draw upon different attentional resources, such that reallocation of these resources is not possible when attention is focused on only one dimension.

\section{GENERAL DISCUSSION}

This paper adopts spatial frequency analysis as its general framework. Although it is generally thought untenable that a full-scale Fourier analysis is performed on the entire visual image, what appears a useful first approximation is a model based on local Fourier analysis performed on the small "patches" into which the visual field is divided (Woodhouse \& Barlow, 1982). Boosmaier and Snyder (1986) have provided a statistical argument for why local spatial frequency analysis is an optimum procedure for efficient information transmission. Cast in this light, the question pursued here is whether spatial fre- quency and orientation are processed independently at the level of these patches.

The double-judgment paradigm allows three types of potential associations to be detected. Each has a different meaning in the context of processing multidimensional stimuli. Sensory associations occur when the representations of information of the different dimensions are coded jointly. Associations at the cognitive level obtain when the processing of one dimension is affected by the processing of the other components. Associations at the response end, whether overall response biases or those arising from particular response patterns from different combinations of stimulus components, could contribute to the overall interactions within the system.

These issues are closely related to research investigating the psychological dimensions underlying the perceptual processing of multidimensional stimuli. For example, Garner and his associates (e.g., Garner, 1976, 1980; Garner \& Felfoldy, 1970) showed that the integrality or separability of the dimensions affect differentially the processing of a stimulus.

Another way of conceptualizing these issues is in terms of the degree of correspondence between the physical and the psychological dimensions of a stimulus (Cheng \& Pachella, 1984). Since the physical dimensions are orthogonal by definition, a psychophysical correspondence would imply the orthogonality of the psychological dimensions. The idea of psychophysical correspondence admits degrees of integrality (or separability) and, as Cheng and Pachella argued, would eliminate the proliferation of terms used to describe different forms of integrality. To map the psychological space, MDS methods are used. 
However, whether MDS is appropriate for all stimuli is still an issue that is earnestly debated (Tversky \& Gati, 1982). Furthermore, using the MDS plot to assess psychophysical correspondence requires the implicit assumption that the underlying distribution of the stimulus in the psychological space is multivariate normal with equal covariance.

The approach adopted here uses the magnitude of information transmission as an index of associations that may potentially exist in the system. As in Cheng and Pachella's (1984) approach, this method admits degrees of separability, but does not require any additional parametric assumptions.

The results suggest that, at the cognitive level, spatial frequency and orientation are processed independently. They form separable dimensions, and the decision made on one is independent of the other. Although the present results are not different from those obtained from filtering paradigms, note that the latter address only the dimensional separability issue. To extrapolate from dimensional separability to sensory independence requires additional assumptions about the decisional process as well as about issues concerning the state of the sensory mechanisms. The double-judgment paradigm allows a more adequate examination of the independence issue by decoupling independence at the sensory level from independence at the cognitive level.

Although the present data suggest decisional independence, sampling independence was not found to be true: spatial frequency and orientation information do not appear to be coded independently. This may be interpreted in one of several ways. The association could be seen as correlated noise between the filters (e.g., Graham, Kramer, \& Haber, 1985) or as mutual excitation (or inhibition) between the filters (Graham, 1985). Such sensory interactions are also compatible with Lockhead's (1972) "blob" model. Lockhead theorized that in the initial processing phase, multidimensional stimuli are represented as an undifferentiated mass (a "blob") in a multidimensional space. In the later processing stages, the dimensions may be analyzed separately. Such a model suggests, of course, that if the stimulus representation is examined sufficiently early in the processing sequence, sensory associations will inevitably be discovered.

If what has been designated as sensory associations do in fact tap into what goes on at the sensory end, these results are also compatible with models derived from physiological studies. The more popular models of cortical receptive fields, for example, Hubel and Wiesel's (1962) center-surround model, as well as the model based on the Gabor function, predict a frequency-orientation covariation. From the single-cell studies (Webster \& DeValois, 1985), the general conclusion is that spatial frequency and orientation are not independently represented. Cells that are narrowly tuned to spatial frequency are more often broadly tuned to orientation, and vice versa.

Independence at the cognitive level shows that each dimension can be selectively attended to in the face of variation on the irrelevant dimension. A question that fol- lows is whether concurrent processing of two dimensions will lead to any decrement in performance, relative to processing just one dimension. One way of thinking about this is to ask whether frequency and orientation processing are capacity-limited or capacity-free (Schneider \& Shiffrin, 1977; Shiffrin \& Schneider, 1977). If the tasks are capacity-free, then divided attention should not lead to any performance deficit. Performance parity of the single- and double-judgment tasks suggest that processing spatial frequency and orientation involve processes that appear to proceed independently of each other, each tapping into different attentional resources.

\section{REFERENCES}

AShby, F. G., Townsend, J. T. (1986). Varieties of perceptual independence. Psychological Review, 93, 154-179.

Blakemore, C., Nachmias, J. (1971). The orientation specificity of two visual aftereffects. Joumal of Physiology, 213, 157-174.

Boosmaier. T., SNyder, A. W. (1986). Why spatial frequency processing in the visual contex? Vision Research, 26, 1307-1309.

Bradley, A., Skottun, B. C. (1984). The effects of large orientation and spatial frequency differences on spatial discriminations. $\mathrm{Vi}$ sion Research, 24, 1889-1896.

Burbeck, C. I., ReGAN, D. (1983). Independence of orientation and size in spatial discriminations. Journal of the Optical Society of America, 73, 1691-1694.

CAELL, T. (1983). Energy processing and coding factors in texture discrimination and image processing. Perception \& Psychophysics, 34, 349-355.

Caelli, T., Brettel, H., Rentschler, I, \& Hilz, R. (1983). Discrimination thresholds in the two-dimensional spatial frequency domain. Vision Research, 23, 129-133.

Caelu, T., Moraglia, G. (1985). On the detection of Gabor signals and discrimination of Gabor textures. Vision Research, 25, 671-684.

Cheng, P. W., Pachella, R. G. (1984). A psychophysical approach to dimensional separability. Cognitive Psychology, 16, 279-304.

Daugman, J. G. (1980). Two-dimensional spectral analysis of cortical receptive field profiles. Vision Research, 20, 847-856.

Daugman, J. G. (1984). Spatial visual channels in the Fourier plane Vision Research, 24, 891-910.

DAUGMAN, J. G. (1985). Uncertainty relation for resolution in space, spatial frequency, and orientation optimized by two-dimensional visual cortical filters. Joumal of the Optical Society of America, 2, 1160-1169.

GARNER, W. R. (1962). Uncertainty and structure as psychological concepts. New York: Wiley.

GARNER, W. R. (1976). Interaction of stimulus dimensions in concept and choice processes. Cognitive Psychology, 8, 98-123.

GARNER, W. R. (1980). The analysis of unanalyzed perceptions. In M. Kubovy \& J. Pomerantz (Eds.), Perceptual organization (pp. 119139). Hillsdale, NJ: Erlbaum.

Garner, W. R., Felfoldy, G. L. (1970). Integrality of stimulus dimensions in various types of information processing. Cognitive Psychology, 1, 225-241.

Garner, W. R., \& Morton, J. (1969). Perceptual independence: Definitions, models, and experimental paradigms. Psychological Bulletin, 72, 233-259.

Getty, D. J., Swets, J. A., Swets, J. B., Green, D. M. (1979). On the prediction of confusion matrices from similarity judgments. Perception \& Psychophysics, 26, 1-19.

Glezer, V. D., Tsherbach, T. A., Gauselman, V. E., B Bondarko, V. M. (1982). Spatio-temporal organization of receptive fields of the cat striate cortex. Biological Cybernetics, 43, 35-49.

Graham, N. (1981). Psychophysics of spatial-frequency channels. In M. Kubovy \& J. Pomerantz (Eds.), Perceptual organization (pp. 125). Hillsdale, NJ: Erlbaum.

Graham, N. (1985). Detection and identification of near- threshold visual patterns. Journal of the Optical Society of America, 2, 1468-1482. 
Graham, N., Kramer, P., \& Haber, N. (1985). Attending to the spatial frequency and spatial position of near threshold visual patterns. In M. I. Posner \& O. S. M. Marin (Eds.), Attention and performance (Vol. 11, pp. 269-284). Hillsdale, NJ: Erlbaum.

HubeL, D. H., \& Wiesel, T. N. (1962). Receptive fields, binocular interaction, and functional architecture in the cat's visual cortex. Journal of Physiology, 160, 106-154.

Hubel, D. H., Wiesel, T. N. (1968). Receptive fields and functional architecture of monkey striate cortex. Journal of Physiology, $195,215-243$

KaUfman, H., Levy, R. M. (1971). Analysis of the combination of perceptual dimensions. Psychological Bulletin, 75, 369-378.

Lockhead, G. R. (1972). Processing dimensional stimuli: A note. Psychological Review, 79, 410-419.

McGill, W. (1954). Multivariate information transmission. Psychometrika, 19, 97-116.

MilleR, G. A., \& Madow, G. W. (1954). On the maximum-likelihood estimate of the Shannon-Wiener measure of information (Technical Report No. 54-75). Washington, DC: Cambridge Air Force Research Center.

Nosofsky, R. (1985). Overall similarity and the identification of separable-dimension stimuli: A choice model analysis. Perception \& psychophysics, 38, 415-432.

Olzak, L. A., \& Thомas, J. P. (1986). Seeing spatial pattems. In K. Boff, L. Kaufman, \& J. Thomas (Eds.), Handbook of perception and human performance: Vol. 1. Sensory processes and perception (pp. 7-1-7-56). New York: Wiley.

Pearson, K., Stouffer, S. A., \& David, F. N. (1932). Further applications in statistics of the $\operatorname{Tm}(x)$ Bessel function. Biometrika, 24, 293-350.

Schiller, P. H., Finlay, B. L., \&olman, S. F. (1976). Quantitative studies of single cell properties in monkey striate cortex: 2. Orientation specificity and ocular dominance. Journal of Neurophysiology, 39, 1334-1351.

SChNeIder, W. Shiffrin, R. M. (1977). Control and automatic human information processing: 1. Detection, search and attention. Psychological Review, 84, 1-66

Shannon, C. E., W Waver, W. (1949). The mathematical theory of communication. Urbana: University of Illinois Press.

Shiffrin, R. M., SCHNeIder, W. (1977). Control and automatic human information processing: 2. Perceptual learning, automatic attending and a general theory. Psychological Review, 84, 127-190.

TVERSKY, A., \& GATI, I. (1982). Similarity, separability, and the triangle inequality. Psychological Review, 89, 123-154.

WebSTER, M. A., \& DEVALOIS, R. L. (1985). Relationship between spatial frequency and orientation tuning of striate-cortex cells. Journal of the Optical Society of America, 2, 1124-1132.

Woodhouse, J. M., BARLow, H. B. (1982). Spatial and temporal resolution and analysis. In $\mathrm{H}$. B. Barlow \& J. D. Mollon (Eds.), The senses (pp. 133-164). Cambridge: Cambridge University Press.

\section{APPENDIX}

This method of partitioning transmitted information into orthogonal parts was first developed by McGill (1954) and subsequently reworked by Garner (1962), Garner and Morton (1969), and Kaufman and Levy (1971), among others. The information-transmission statistic of each of these parts can then be tested against the null hypothesis of zero information transmission.
In a situation in which Event $F$ has $k$ alternatives, the uncertainty, $U(F)$, may be defined as

$$
U(F)=-\sum p\left(F_{i}\right) \log _{2} p\left(F_{i}\right),
$$

where $p\left(F_{i}\right)$ is the probability of the $i$ th alternative. This is the familiar definition of entropy introduced by Shannon and Weaver (1949).

Consider a two-variable system in which $F$ represents the stimulus and $f$, the response. The association between $F$ and $f$, or, to use Garner's (1962) nomenclature, the contingent uncertainty between $F$ and $f$ [denoted $U(F: f)$ ], is defined as

$$
U(F: f)=U(F)+U(f)-U(F, f),
$$

where the last term is the joint uncertainty of $F$ and $f$. The simple contingency term, $U(F: f)$, may be interpreted as a measure of information transmitted between $F$ and $f . U(F: f)$ is zero when $F$ provides no information whatsoever, and is at a maximum when $F$ uniquely determines $f$ (e.g., when no identification errors are made).

This analysis may be extended to a four-variable system. In a double-judgment experiment in which $F$ and $O$ are the stimulus components and $f$ and $o$ are the respective responses, the total constraint in the system (or total information transmitted), $U(F, O: f, o)$, may be decomposed into the following orthogonal parts (Garner \& Morton, 1969; but see Kaufman \& Levy, 1971, for an alternative decomposition):

$$
\begin{aligned}
U(F, O: f, o)= & U(F: O)+U(F: f)+U(O: o) \\
& +U_{F}(O: f)+U_{o}(F: o) \\
& +U_{F o}(f: o)
\end{aligned}
$$

First, consider the term $U(F: O)$. If $F$ and $O$ are manipulated as orthogonal inputs, the magnitude of $U(F: O)$ is, by definition, zero. The next two measures, $U(F: f)$ and $U(O: o)$, are the aforementioned simple contingent-uncertainty terms.

Consider next the partial contingency terms $U_{F}(O: f)$ and $U_{o}(F: o)$. They relate directly to the issue of cognitive independence and may be interpreted as a nonmetric variant of a partial correlation measure. The term $U_{F}(O: f)$ reflects the extent to which the $f$ response is affected by the information in the $O$ stimulus after the information in $F$ has been partialled out. $U_{o}(F: o)$ may be interpreted analogously. Since $F$ and $O$ are orthogonal by experimental design, $F$ carries no information about $O$, and vice versa. If independence obtains, these partial contingency terms should be statistically zero.

The final term in the equation, $U_{r o}(f: o)$, pertains to the association of the $f$ and $o$ responses at each $F_{i} O_{j}$, and may be interpreted as a measure of error correlation. In addition, one may compute the simple contingency measure $U(f: o)$ to assess the overall response bias.

(Manuscript received August 24, 1988; revision accepted for publication July 14,1989 .) 